\title{
Tribo-Fatigue Behavior of Austempered Ductile Iron MoNiCa as New Structural Material for Rail-Wheel System
}

\section{Regita BENDIKIENE ${ }^{1}$, Aliaksandr BAHDANOVICH ${ }^{2}$, Ramunas CESNAVICIUS ${ }^{1}$, Antanas CIUPLYS ${ }^{1}{ }^{*}$, Vytautas GRIGAS ${ }^{1}$, Audrius JUTAS ${ }^{1}$, Dzianis MARMYSH ${ }^{2}$, Aleh NASAN ${ }^{2}$, Liudmila SHEMET ${ }^{2}$, Sergei SHERBAKOV ${ }^{2}$, Leonid SOSNOVSKIY ${ }^{3}$}

\author{
${ }^{1}$ Kaunas University of Technology, Faculty of Mechanical Engineering and Design, Department of Production \\ Engineering, Studentu st. 56, LT-51424 Kaunas Lithuania \\ ${ }^{2}$ Belarusian State University, Faculty of Mechanics and Mathematics, Department of Theoretical and Applied Mechanics, \\ Nezavisimosti ave 4, 220030 Minsk, Belarus \\ ${ }^{3}$ Belarusian State University of Transport, Mechanical Faculty, Department of Locomotives, Kirova str. 34, 246653 Gomel, \\ Belarus
}

crossref http://dx.doi.org/10.5755/j01.ms.26.4.25384

Received 29 February 2020; accepted 30 June 2020

\begin{abstract}
Austempered ductile irons exhibit an interesting combination of properties such as low cost, elevated strength, fatigue and wear resistance. This research presents the results of tribo-fatigue behavior of austempered ductile cast iron MoNiCa and gives a comparison with standard grades of steel and cast iron. Due to the possibility to combine the castability of cast iron and toughness of steel in one material, new structural material MoNiCa attracted attention of industry and science because of economic benefits and high performance at the different application areas. After successful former experiments the main directions of further development of research for solving relevant practical wear and fatigue problems in railwheel system were framed. The complex experimental studies have demonstrated that MoNiCa is consistent with heat treated steels including the rail steels: required tensile strength of rail steel ranges from $1180 \mathrm{MPa}$ to $1280 \mathrm{MPa}$ when rolling surface hardness have to be from $38 \mathrm{HRC}$ to $44 \mathrm{HRC}$ whereas new structural material showed higher tensile strength up to $1400 \mathrm{MPa}$ and slightly higher hardness up to $50 \mathrm{HRC}$. Herewith the workability of frictional couple cast iron $\mathrm{MoNiCa} / \mathrm{steel} 20 \mathrm{MnCr} 5 \mathrm{G}$ exceeds work performance of steel/steel system by $14 \%$. Future prospect of this study is to compose mechanical-mathematical model of rail-wheel system, to analyze it under three-dimensional loading, and to execute the field tests of rails under operating conditions.
\end{abstract}

Keywords: tribo-fatigue, austempered ductile iron, rail-wheel system, mechanical properties.

\section{INTRODUCTION}

Up to the middle of the last century the only cast iron grade able to show both a high castability as well as good mechanical properties was malleable iron $[1,2]$. These findings were achieved by graphitizing annealing performed on white cast irons. Later studies in 60's adding magnesium and cerium allowed to obtain cast irons with nodular shape graphite (ductile cast iron) and analogous mechanical properties with lower production cost. Ductile cast iron is a fascinating engineering material for the manufacturing of different components including wear resistant parts requiring an optimized compromise between fatigue and wear, truck suspension parts, power transmission components, stones crushers and mining components, and components of various geometrical complexity, etc. [3-5]. Austempering is the most widely - used heat treatment procedure to reach excellent combination of high strength, ductility, good wear resistance and tribo-fatigue behavior. So called austempered ductile irons (ADI) in addition to low manufacturing cost, fluidity, recyclability, damping capacity, and heat conductivity are much better than of some grades of alloyed cast steels, consequently they can be

\footnotetext{
${ }^{*}$ Corresponding author. Tel.: +370-37-323769.

E-mail address: antanas.ciuplys@ktu.lt (A. Ciuplys)
}

considered as an economical replacement for alloyed steel and other grades of cast irons [3, 6, 7].

Mechanical properties of ADI are strongly influenced by chemical composition, austempering temperature, holding time, and quenching rate. Heat treatment cycle places significant role in resultant properties of cast iron. Such an iron has a microstructure consisting mainly of ferrite-austenite and nodular graphite particles [8]. Microstructure of ADI could be altered changing modificators and parameters of heat treatment processes.

If high wear resistance application is necessary, ADI could be considered because of its suitability to the different wear mechanisms: abrasion, adhesion, contact or sliding fatigue, tribo-fatigue, and tribo-corrosion. Introduction of carbides in ADI composition with the purpose to reinforce the matrix subjected to abrasive wear may adapt to different wear mechanisms [9], consequently existence of hard carbide particles in such a tribosystem increases the abrasion resistance however reduces the impact toughness [10].

Much insight into the mechanical fatigue process can provide more information about irreversible processes that ages the system until the final fracture [11]. Fatigue is categorized as low- and high-cycle according to the number 
of cycles: the former is limited to $N_{f}<10^{3}$ cycles, the later to $10^{3}-10^{6}$, here applied stress is basically below the limit of elasticity. Plastic strain is not important since the applied stress is generally below the elastic limit.

It was shown [6] that the strength of the new structural material practically reached the strength of high-strength steel. However, plasticity of MoNiCa is still much lower. But for highly loaded system, such as railway rails, plastic deformation is uncharacteristic, it works under conditions of friction cyclic loads. This means that their performance is determined, first of all, not by plasticity under static tension, but by fatigue resistance under contact loading and bending. The challenge related with the development of suitable material is to ensure the ability to control the microstructure in order to obtain the balance between abrasion resistance and toughness in tribo-fatigue system [10].

Materials' exploitation characteristics such as mechanical and contact fatigue resistance are certainly of particular interest in tribowear systems. Therefore, the main aim of this study was to identify tribo-fatigue behaviour of austempered new structural material MoNiCa for possible application in rail-wheel system. This behavior determines the operational efficiency of rail-wheels system especially under a heavy loading.

\section{PREAMBLE OF RESEARCH}

As it is known tribo-fatigue system wheel-rail is the physical basis of train movement on railways. Literarily, steel rails are the nervous system of the railroad economy, and therefore their condition largely determines its rhythm and efficiency. Heavy railroad rails are one of the most responsible, massive and heavily loaded parts of railroad system: axial operating loads reach $27-29 \mathrm{t}$ (maximum permitted weight per axle), speeds may exceed $100 \mathrm{~km} / \mathrm{h}$. The requirements for the operational stability of the rails are continuously increasing, since it is necessary to transport more and more cargo (people as well) to ever longer distances with steadily increasing speeds.

The socio-economic importance of railways can be explained by simple fact: even a short railway line to any settlement ensures its fast development, by the way railways have a special military and strategic importance. In fact, although an increase in the quality of rails is equivalent to an increase in their operational durability and, consequently, reliability, durability and safety, it will instantly respond to the maintenance difficulty with the subsequence increase in the cost of their production (as well as proper maintenance of railway). So, it is essential to analyze the questions of steel rails and to suggest the best scientific solution. To achieve this goal a specific scientific proposal is put forward: casting of rails made of austempered ductile cast iron. Therefore, if the mechanical properties of ductile cast iron for rails were about the same as that of steel, then wellknown high-strength nodular cast iron would be incomparably better than steel in a number of service properties: wear resistance, self-lubrication, damping ability and others.
The point is to have such high-strength cast iron for the manufacture of rails, the mechanical properties of which at least would not be inferior to steel (or would be slightly inferior to it), i.e. steel like high-strength cast iron would be preferable. Such a new structural material MoNiCa for potential application in rail-wheel system is under the consideration in this research.

\section{TESTING PROCEDURES AND METHODS}

The idea to produce cast rails is unique because it violates more than 150-year-old tradition of making rails from high quality steel by highly efficient but very energy consuming and expensive method of rolling. To implement this idea, it is necessary to solve two difficult problems. The first consideration is to offer a new material for rails manufacturing which would be not inferior to steel by key performance criteria, and the second problem is that the material should have high technological properties to enable casting of long-size rails which cross-sections size can sharply change by several times. Rail-wheel system has been chosen as a basis of the study (Fig. 1).

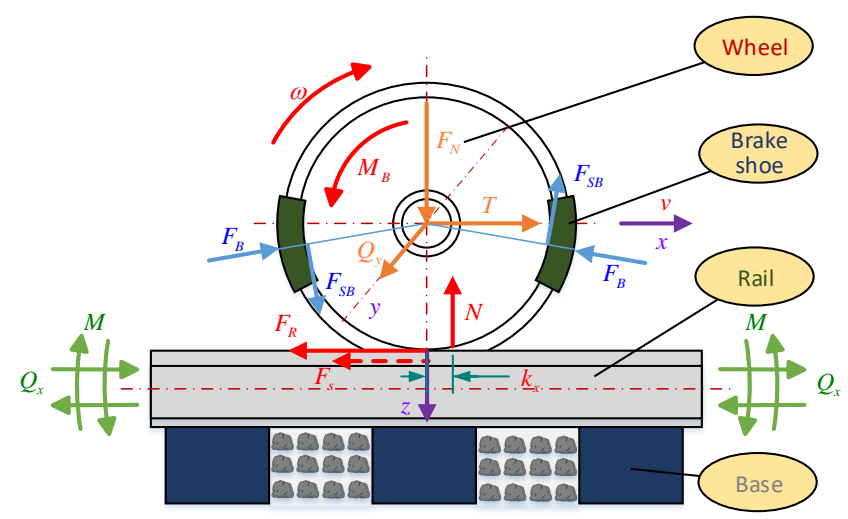

Fig. 1. Rail-wheel system

Chemical composition of new structural material MoNiCa is shown in Table 1.

Test samples were subjected to heat treatment according to the following scheme (Fig. 2): 1) austenization at $890^{\circ} \mathrm{C}$ for $30 \mathrm{~min}$; 2) quenching in salt bath, $5 \mathrm{~s} ; 3$ ) austempering at three different temperatures $270{ }^{\circ} \mathrm{C}, 300{ }^{\circ} \mathrm{C}$ and $330^{\circ} \mathrm{C}$; and 4) air quenching [6]. It was avoided to select higher process temperature trying to avoid worse wear performance of ADI as reported by other authors [13].

SI-O3 M test machine was used to study behavior of new structural material in the contact with counter-specimen [14]. This system integrates fatigue, friction, and wear tests along to fundamental type of wear-fatigue test where rotational motion (rotational bending) is primary condition. There is no mechanical transmission in SI machine what reduces any test errors and avoids power losses. The rotational speed $\mathrm{n}$ can vary in the range of 50-5000 r.p.m.

A slip degree can be set up to $85 \%$ in rolling test. Constant bending and contact loads are also adjustable.

Table 1. Chemical composition of new structural material MoNiCa, wt. \% [12]

\begin{tabular}{|c|c|c|c|c|c|c|c|c|c|}
\hline $\mathrm{C}$ & $\mathrm{Si}$ & $\mathrm{Mn}$ & $\mathrm{Cr}$ & $\mathrm{Mo}$ & $\mathrm{Ni}$ & $\mathrm{Cu}$ & $\mathrm{Mg}$ & $\mathrm{Ti}$ & $\mathrm{Fe}$ \\
\hline $3.5-3.7$ & $2.5-2.8$ & $0.2-0.3$ & $0.02-0.06$ & $0.4-0.6$ & $0.5-0.6$ & $1.1-1.3$ & $0.03-0.07$ & $0.01-0.12$ & $\mathrm{Bal}$. \\
\hline
\end{tabular}


Achievable cyclic stress is $700 \mathrm{MPa}$ or even higher, and contact pressure not exceeding $3500 \mathrm{MPa}$. It is possible to operate either with tensile or compressive bending loads. Controlling system of SI test machine ensures proper monitoring of the test. Test samples for contact tribo-fatigue test were casted according to the scheme presented in Fig. 3.

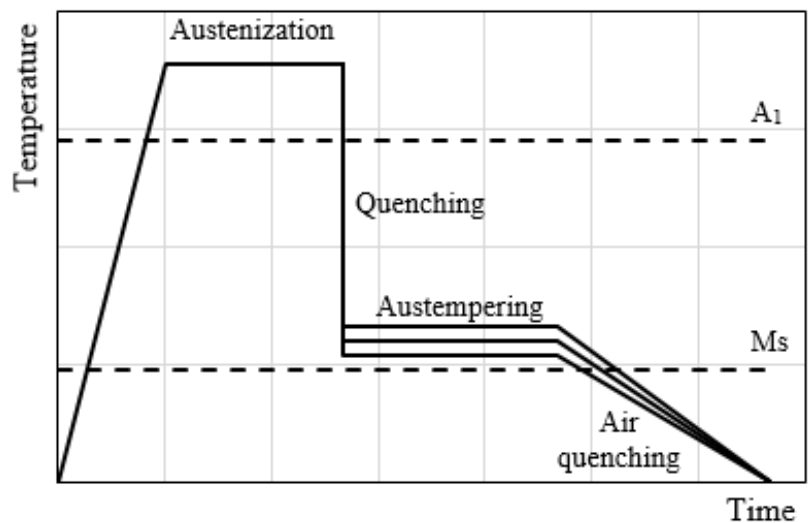

Fig. 2. Schematic diagram of heat treatment schedule

Brinell and Rockwell hardness tests were accomplished at the different stages of experiment using Universal hardness tester Verzus 750CCD.

Vickers surface hardness (HV30) of the surface of the hardfacings was measured using the Vickers hardness tester Indentec 5030KV (Zwick/Roell, Germany) at the load $294.3 \mathrm{~N}$ (30 kgf) and the dwell time $10 \mathrm{~s}$. Ten measurements were done on each sample and the average hardness value was calculated.

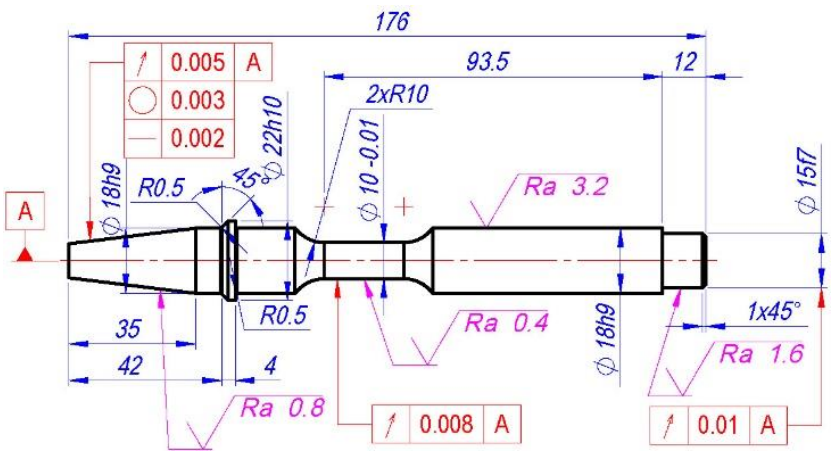

Fig. 3. Geometry of tribo-fatigue test piece

\section{RESULTS AND DISCUSSION}

The rail-wheel system has been described in term of forces presented in Fig. 1. In order to evaluate reasons for the force influence on the tribo-fatigue it is necessary to decide what acting forces are responsible for a resulting load that may explain wearing conditions coming from the sliding/friction between the wheel and rail in their contact area. The shear force $Q_{y}$ acts along to the rail axis $y$ and also as a normal force results the strength in the wear contact of the inside-upper surface according to the cross-sectional perimeter of the rail. Both traction force $T$ and rolling friction force $F_{R}$ directed in opposite directions by inequality $T>F_{R}$ if a wagon velocity and rolling friction force are $v(R, \omega) \neq 0$ and $F_{R}=f N$, respectively; here $f$ is coefficient of rolling friction between the wheel and rail materials. The weight force of the vehicle $F_{N}$ influences on the normal component $N$ moved from the centric wheel axis $\mathrm{z}$ by a length $k$ of deformed contact area $A_{C}$ that may form on the rail under the wheel. The longitudinal force $Q_{x}$ associates to the force $F_{R}$ and the former can act normally to the rail cross-sectional area in both directions, the rolling and brake regimes, respectively. A bending moment $M$ is also shown acting bi-directionally because of the different wheel position in case of rolling. The two brake shoes act normally/radially from the rotational wheel axis to the peripheral wheel surface by the forces $F_{B}$ and form braking moment $M_{B}=2 R F_{B}$, where $R$ is the radius of the wheel.

To examine the specimen in conditions of sliding friction occurring similarly in a real operation on a sidelong surface of the rail, the scheme presented in Fig. 4 was used.

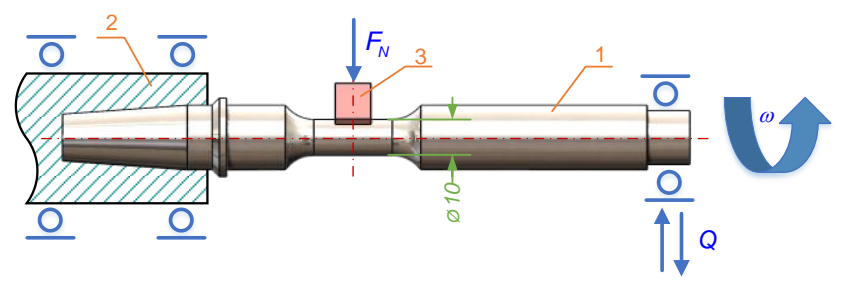

Fig. 4. Sliding friction fatigue system: 1-sample; 2-sample fixation; 3 -counter sample

The acting shear force $Q_{y}$ influences mostly on wear caused by a sliding friction and it also shortens rail lifetime. In the experiment, the operational shear force $Q_{y}$ was changed to a compressive force $F_{N}$. The last one has been realized through a counter sample 3 made of steel $20 \mathrm{MnCr} 5 \mathrm{G}$ that affects the main objects that are the two samples 1 made of cast iron MoNiCa or of steel 20MnCr5G. The sample 1 is supported in a fixture 2 at both ends. The number of revolutions $n$ or angular velocity $\omega$ of the specimen can be controlled in same range as it was used in the experiment of the rolling friction with a realization of the scheme presented in Fig. 1. In this research, a sample deflection influence on wear differences for various sample materials has not been taken in to account because the same sample dimensions and support conditions in the experiment allow an identity of the existing operational similarity in real rail R65 cross-sectional dimensions and support conditions between sleepers.

Comparison of the durability limits of MoNiCa, highstrength steel as well as commercially available austempered cast iron ADI-1050 and structural steel $20 \mathrm{MnCr} 5 \mathrm{G}$ are presented in Table 2.

Table 2. Austempered ductile cast iron and steel: durability limits

\begin{tabular}{|l|c|c|c|c|c|c|}
\hline \multirow{2}{*}{ Material } & \multicolumn{2}{|c|}{$\begin{array}{c}\text { Hardness, } \\
\mathrm{HB}\end{array}$} & \multicolumn{2}{c|}{$\begin{array}{c}\text { Limit of } \\
\text { contact } \\
\text { fatigue, MPa }\end{array}$} & \multicolumn{2}{c|}{$\begin{array}{c}\text { Limit of } \\
\text { durability on } \\
\text { tension, MPa }\end{array}$} \\
\cline { 2 - 7 } & $\min$ & $\max$ & $\min$ & $\max$ & $\min$ & $\max$ \\
\hline ADI-1050* & 200 & 300 & 550 & 700 & 210 & 248 \\
\hline 20MnCr5G** & 200 & 300 & 706.6 & 1123.1 & 302.6 & 370.3 \\
\hline MoNiCa & 320 & 360 & 900 & 1050 & 270 & 310 \\
\hline * ISO 17804/JS/1050-6/S \\
** DIN EN 10083-3-2009, ISO 683-2:2016 \\
\hline
\end{tabular}


It is clearly seen that new structural material MoNiCa is a very successful competitor for standard grade austempered cast iron and even overtakes alloyed heat-strength steel. Comparing cast iron and steel by loading capacity and durability, the output will be similar. It was reported [13] that cast irons produced by conventional heat treatment process comparing with single-step ADI have higher wear loss under equivalent hardness. The excellent wear resistance of ADI is associated with stress-induced transformation from residual austenite into martensite to improve the surface hardness.

Fig. 5 compares the loading capacity (according to contact load $F_{N}$ ) and durability (number of loading cycles $N$ ) with a multistage increase in load until the ultimate state is reached (indicated by dashed lines) of $\mathrm{MoNiCa}$ and improved cemented steel 18HGT (ultimate tensile strength $\sigma_{u}=1600 \mathrm{MPa}$, hardness $700 \mathrm{HV}$, fatigue strength at the bending $640 \mathrm{MPa}$ and contact fatigue of $1270 \mathrm{MPa}$ ). As it can be seen in Fig. $5 \mathrm{MoNiCa}$ as a special kind of cast iron shows high fatigue resistance. All the tests were performed under the same frequency of $3000 \frac{1}{\mathrm{~min}}$, as the base $10^{5}$ cycles longevity was used.

Obtained data showed that cyclic stresses significantly slowed process of tribo-fatigue under the given test conditions, as a result workability range was increased approximately by $14 \%$. It can be explained by the removal of thin surface layer containing primary fatigue cracks during the test out of the working zone. It was explained [15] that fatigue limit of ADI is controlled by a crack arrest. Ausferrite boundaries act as barrier for micro cracks formation in the austenitic matrix, while strength of the barrier depends on the relative orientation of the microstructure at the grain boundary. Tribo-fatigue failure mechanism is related with accumulation of microplasticity, so it is assumed that it strongly depends on material hardness [9]. At the same time, it is related with initial cyclic hardening followed by the stabilized stress response until the failure. This is connected with the growth of macroscopic cracks [16]. For homogeneous materials such as hardened or tempered steel, the hardness is a dominant property in the tribo-fatigue system, however for austempered ductile irons with complex structure (nodular graphite, retained austenite, carbide) this dependence due to the presence of different inclusions is lower. On the other hand, formation of granular carbides in the structure of MoNiCa [6] promotes an increase of abrasion wear resistance with slightly decrease of toughness. Such a result could be explained [7] by an increase of micro hardness on and close the surface because of the strain induced transformation of retained austenite with low carbon content into martensite during the tests. This behavior needs further studies.
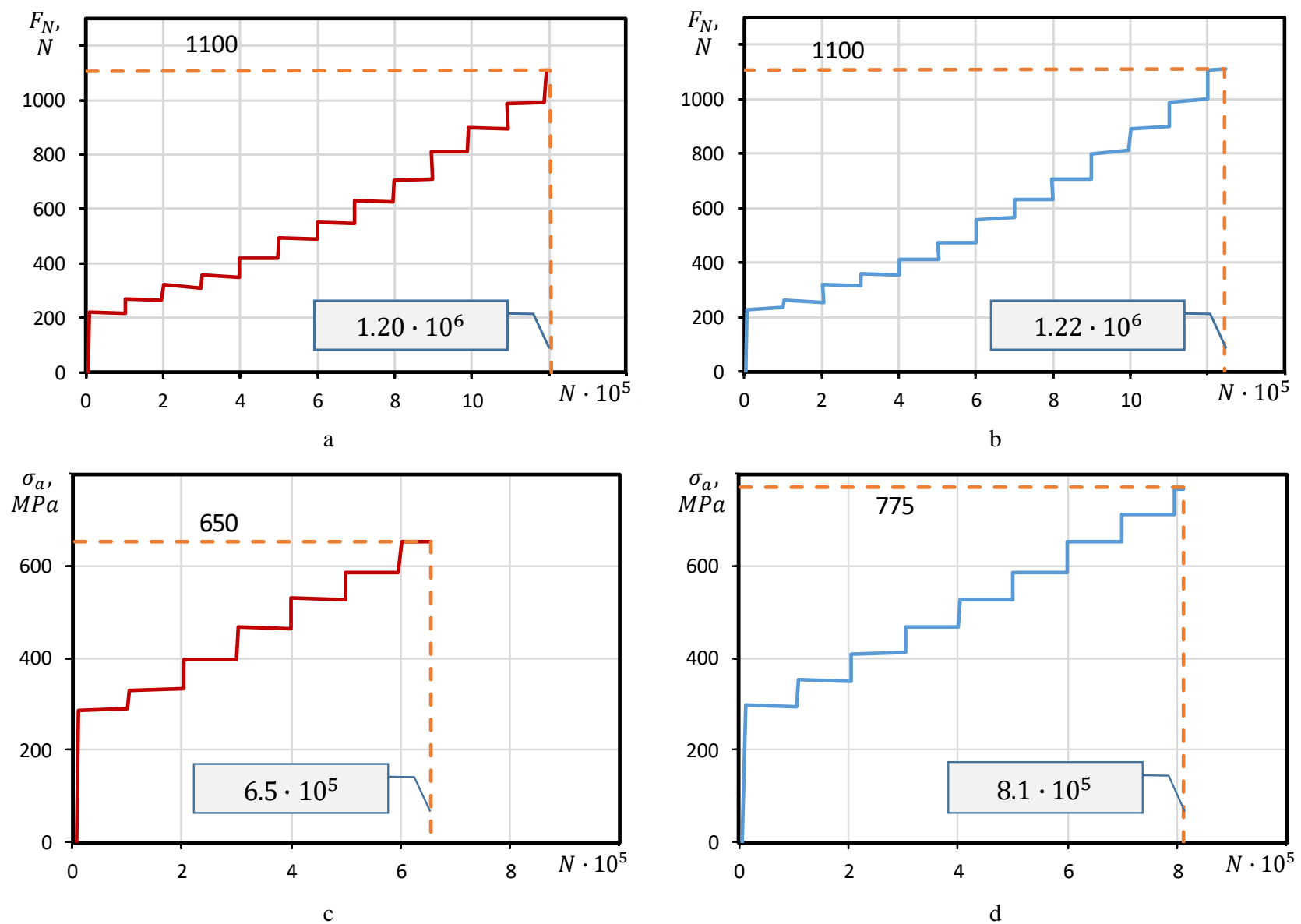

Fig. 5. ADI MoNiCa vs steel: loading program and durability: a-frictional couple cast iron MoNiCa/steel 20MnCr5G; b-frictional couple steel 20MnCr5G/steel 20MnCr5G; c - cast iron MoNiCa; d - steel 20MnCr5G 
Ensuring the required coefficient of friction for highloaded tribo-fatigue system is of the great practical importance, since its specific numerical value firstly causes the loss of drive power, and secondly directly affects the wear of the elements of the contact couple. Fig. 6 presents comprehensive experimental data at the maximum contact pressure $\left(p_{0}\right)$, which shows that the use of $\mathrm{MoNiCa}$ in a contact couple at least not worsens the situation of friction: both the friction coefficient and the adhesion are suitable (in comparison with steel). High enough contact pressure of $2000 \mathrm{MPa}$ has been chosen in order to cause the degradation of material by microplasticity, but not extremely high to avoid material build up along the edges of the rolling track [3]. Too high pressure could cause changing of contact geometry and pressure leading to distorted test's results.
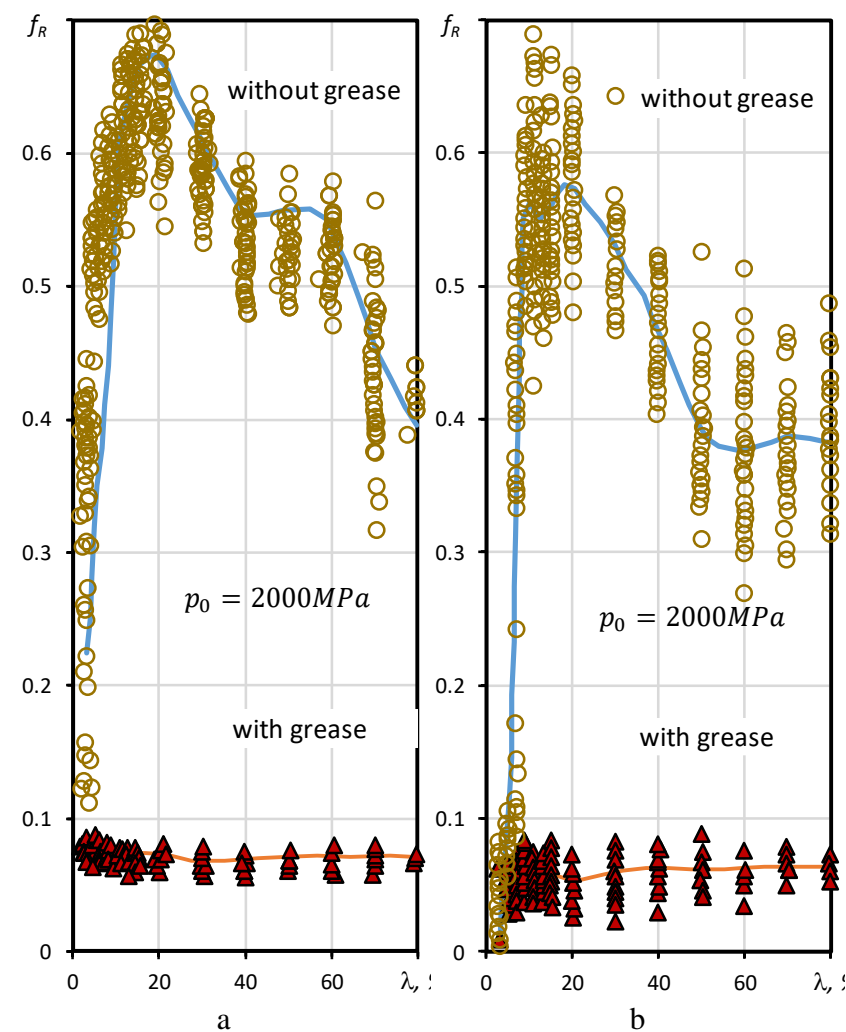

Fig. 6. Effect of the degree of slip $\lambda$ on the coefficient of rolling friction $f_{R}$ with/-out grease lubrication: a-couple steel $20 \mathrm{MnCr} 5 \mathrm{G} / \mathrm{steel} 20 \mathrm{MnCr} 5 \mathrm{G} ; \mathrm{b}$-couple cast iron $\mathrm{MoNiCa} / \mathrm{steel}$ 20MnCr5G

\section{CONCLUSIONS}

Due to its good anti-friction, high thermal conductivity as well as high castability MoNiCa could be used as rail material in rail-wheel system. It was shown that $\mathrm{MoNiCa}$ is not inferior to high-strength steel including rail steel in terms of mechanical properties, fatigue resistance and fracture toughness. Test performed on SI-O3 M tribofatigue machine using small-sized models let say that the application of the new structural material for rail production can lead up to $50 \%$ of wear reduction.

Taking into the account lower cost of cast iron manufacturing it can be expected the cost of cast rails made on MoNiCa could be by 30-50\% less than the cost of the steel rails produced by rolling. Summarizing achieved results the future targets of the research were framed: to compose mechanical-mathematical model of rail-wheel system, to analyze it under three-dimensional loading, and to execute the field tests of rails under operating conditions.

\section{Acknowledgments}

This research was funded by a grant (No. S-LB-19-6) from the Research Council of Lithuania.

\section{REFERENCES}

1. Labrecque, C., Gagné, M. Ductile Iron: Fifty Years of Continuous Development The Canadian Journal of Metallurgy and Materials Science 37 (5) 1998: pp. $343-378$.

https://doi.org/10.1179/cmq.1998.37.5.343

2. Iacoviello, F., Di Cocco, V., Bellini, C. Fatigue Crack Propagation and Damaging Micromechanisms in Ductile Cast Irons International Journal of Fatique 124 2019: pp. $48-54$.

https://doi.org/10.1016/j.ijfatigue.2019.02.030

3. Colombo, D.A., Dommarco, R.C., Basso, A.D. Rolling Contact Fatigue Behavior of Dual-Phase Austempered Ductile Iron Wear 418-419 2019: pp. 208-214. https://doi.org/10.1016/j.wear.2018.11.009

4. Masaggia, S. The Development of ADI and IDI in Italy Procedia Engineering 2 (1) 2010: pp. 1459-1476. https://doi.org/10.1016/j.proeng.2010.03.158

5. Iannitti, G., Ruggiero, A., Bonora, N., Masaggia, S., Veneri, F. Micromechanical Modelling of Constitutive Behavior of Austempered Ductile Iron (ADI) at High Strain Rate Theoretical and Applied Fracture Mechanics 92 2017: pp. $351-359$. https://doi.org/10.1016/j.tafmec.2017.05.007

6. Bahdanovich, A., Bendikiene, R., Cesnavicius, R., Ciuplys, A., Grigas, V., Jutas, A., Marmysh, D., Mazaleuski, A., Nasan, A., Shemet, L., Sherbakov, S., Spakauskas, K., Sosnovskiy, L. Research on Tensile Behaviour of New Structural Material MoNiCa Materials Science (Medžiagotyra) 25 (3) 2019: pp. 292-296. https://doi.org/10.5755/j01.ms.25.3.23079

7. Wang, B., He, M., Barber, G.C., Schall, J.D., Tao, C., Sun, X. Rolling Contact Fatigue Resistance of Austempered Ductile Iron Processed at Various Austempering Holding Times Wear 398-399 2018: pp. 41-46. https://doi.org/10.1016/j.wear.2017.11.022

8. Zammit, A., Abela, S., Betts, J.C., Michalczewski, R., Kalbarczyk, M., Grech, M. Scuffing and Rolling Contact Fatigue Resistance of Discrete Laser Spot Hardened Austempered Ductile Iron Wear 422-423 2019: pp. $100-107$ https://doi.org/10.1016/j.wear.2019.01.061

9. Pedro, D.I., Dommarco, R.C. Rolling Contact Fatigue Resistance of Carbidic Austempered Ductile Iron (CADI) Wear 418-419 2019: pp. 94-101. https://doi.org/10.1016/j.wear.2018.11.005

10. Laino, S., Sikora, J.A., Dommarco, R.C. Development of Wear Resistant Carbidic Austempered Ductile Iron (CADI) Wear 265 2008: pp. 1-7. https://doi.org/10.1016/j.wear.2007.08.013

11. Jang, J.Y., Khonsari, M.M. On the Evaluation of Fracture Fatigue Entropy Theoretical and Applied Fracture Mechanics 96 2018: pp. 351-361. https://doi.org/10.1016/j.tafmec.2018.05.013 
12. МКС 77.080.10, 77.040. High Fatigue Resistance Ductile Cast Iron with Nodular Shaped Graphite. Material Standard (in Russian).

13. Wang, B., Barber, G.C., Qiu, F., Zou, Q., Yang, H. A Review: Phase Transformation and Wear Mechanisms of Single-step and Dual-step Austempered Ductile Irons Journal of Materials Research and Technology 9(1) 2020: pp. $1054-1069$. https://doi.org/10.1016/j.jmrt.2019.10.074

14. Sosnovskiy, L.A., Bogdanovich, A.V., Yelovoy, O.M., Tyurin, S.A., Komissarov, V.V., Sherbakov, S.S. Methods and Main Results of Tribo-Fatigue Tests International Journal of Fatique 66 2014: pp. 207-219. https://doi.org/10.1016/j.ijfatigue.2014.04.006

15. Chapeti, M.D. High-cycle Fatigue of Austempered Ductile Iron (ADI) Intrenational Journal of Fatigue 29 (5) 2007: pp. $860-868$. https://doi.org/10.1016/j.ijfatigue.2006.09.005

16. Pertrenec, M., Tesarova, H., Bcran, $P$, Šmid, M., Roupcova, P. Comparison of Low Cycle Fatique of Ductile Cast Irons with Different Matrix Alloyed with Nickel Procedia Engineering 2 :2010: pp. 2307-2316. https://doi.org/10.1016/j.proeng.2010.03.247

(C) Bendikiene et al. 2020 Open Access This article is distributed under the terms of the Creative Commons Attribution 4.0 International License (http://creativecommons.org/licenses/by/4.0/), which permits unrestricted use, distribution, and reproduction in any medium, provided you give appropriate credit to the original author(s) and the source, provide a link to the Creative Commons license, and indicate if changes were made. 